\title{
National policies in ensuring access to quality and safety of drugs: A challenge or a prerequisite
}

\author{
M. Hadipour Dehshal, ${ }^{1}$ M. Tabrizi Namini ${ }^{2}$ \\ ${ }^{1}$ Charity Foundation for Special Diseases (CFSD); ${ }^{2}$ Blood Transfusion Research Center, High \\ Institute for Research and Education in Transfusion Medicine, Tehran, Iran
}

\begin{abstract}
Access to the essential medicines is an important challenge in the developing countries. To have access to the quality and affordable medicines, the pharmaceutical decision makers try different strategies. The production of generic and copy medicines is one of the strategies that if adopted based on the recognized standards and norms can be effective in raising the health status in the developing countries. However, the regulation enfeeblement has somewhat impaired the quality of generic and copy medicines and harmed the health life of consumers. Here we aim to reflect over the role of different beneficiaries including international organizations, governments, pharmaceutical companies, and NGOs in ensuring the feasible and sustainable access of citizens to the essential medicines. We also aim to highlight the importance of the patient status in the enhancement of the medical delivery.
\end{abstract}

\section{Introduction}

The UN Secretary-General reported that more than 2 billion people across the globe lack the (adequate) access to the essential medicines (1). This alone shows what a challenge it is to ensure the distribution of and the adequate access to the essential medicines. The difficulty in the access to the appropriate healthcare has lowered the life expectancy on the average 32 years below the developed countries; in other words, the average life expectancy among the developed countries is 1.7 times higher (2). The findings show that the share of out of pocket payment in developing countries with lower income is higher than that of the developed countries (3). Paul Van Hoof (European Federation of Pharmaceutical Industries and Associations (EFPIA)) holds the belief that spurring innovations can lead to the better disease management and the higher life expectancy. Likewise, Director General of Medicine for Europe believes in competition as the key for the price drop and the better access to medicines in the EU zone.

Thalassemia major is the disease prevalent at a region in the world known as the thalassemia belt (5). The ones being located within this belt are mainly the developing countries faced with the challenge of access to the essential medicines. In recent years, the governments have adopted different strategies to increase access to

Correspondence: M. Hadipour Dehshal.

E-mail: Mehregan_hadipour@yahoo.com

This work is licensed under a Creative Commons Attribution 4.0 License (by-nc 4.0).

(C) Copyright M. Hadipour Dehshal and M. Tabrizi Namini, 2018 Licensee PAGEPress, Italy

Thalassemia Reports 2018; 8:7483

doi:10.4081/thal.2018.7483 the essential medicines; the strategies have been mainly based on the health cost reduction formulae including the production and distribution of generic and copy medicines. This approach has not been always effective though and has evoked negative reactions by patient advocacy institutions (4). Here we try to address the various ways for higher patient access to the essential medicines and the role governments, NGOs, and pharmaceutical companies would play to this end.

\section{The world outlook for the pharmaceutical market}

After the enactment of Hatch-Waxman Act in 1984, the competition in the pharmaceutical market made the price changes. This persuaded the pioneer companies to produce more newly formulated medicines on one hand and restructure the formulating models for more generic medicines to be made available on the other. So much so that in 2009 generic medicines accounted for approximately $75 \%$ of the prescriptions in the US.

Before the Act, the producers were required to demonstrate the efficacy and safety of generic medicines by independent and unbiased reviews. However, the multiple performances of time consuming and costly clinical trials hindered the timely market availability of generic medicines and raised the production cost. On the other hand, the Act made the US pharmaceutical market open to generic medicines and paved the ground for competition and the price balance.

The availability of generic medicines placed much impact on the market share of brand-name drugs. As shown in Figure 1, the share of brand-name drugs during 12 months after the generic medicines entered the market (1999-2000) was about 68\% while this rate within the 12-month time frame of 2007-2008 reached $37 \%$ in the first month and dropped to $15 \%$ in the final month. The figure 1 clearly displays the changing trend of health structures in the US towards the consumption of generic medicines (9). Therefore, the higher use of generic medicines in the US and subsequently in the other developed countries is the projected future change.

Based on the forecast estimations for 2016-2020, the end of the "patent for small molecules" era would place a remarkable impact more than the preceding years on the increasing production cost in the developed countries and pharmerging markets (10). The years 2005 to 2012 witnessed the significant changes in the share of generic and brand-name drugs in the world market so that the market share of the latter has faced significant increase prompting health advocates and investors and beneficiaries to aim at reversing the expenses (Figure 2) (11).

Besides the big and vanguard companies are run in the countries like Switzerland and the States that do not succumb to TRIPS Agreement and that is why the prices of brand-name medicines are much higher than the generic (12). Thus, the developing countries are persuaded to produce generic and copy medicines. 


\section{Generic medicines: is the quality assured?}

The US FDA defines the term generic as "a drug product that is comparable to a brand/reference listed drug product in dosage form, strength, route of administration, quality and performance characteristics, and intended use". Bioequivalence is then considered as one of the most important elements in the production of generic drugs. The producers of generic drugs based on the FDA Guidance are obliged to prove the equivalence of the main pharmaceutical ingredients and the comparability of their products to brand-name or reference medicines (13). Nevertheless, there has been always a trust challenge in regard to generic drugs with fueled concerns; the less efficacy and more side effects of generic drugs compared with the original brand-names are the concerns that would be eliminated if the international norms and standards of production are met for the quality to be ensured. In the countries like the States where food and drugs are supervised by the entities with organizational clarity, the consumption of generic drugs has been on an increasing trend with 7 medicine prescriptions out of 10 being generic.

However, in developing countries the trust in quality is enfee- bled and further impaired with the lack of a clear-cut distinction between the production and supervision. The study conducted by Heritage Foundation and the Wall Street Journal shows the countries located on the thalassemia belt particularly in the Middle East, North Africa, and the Persian Gulf region having scored lower than 60 for "Index of Economic Freedom" that poses a higher risk for responsibilities of quality supervisors and producers to be mutually interfered (15).

At the same time, the researches done on developing countries stipulate the inability of regulatory bodies in a broad range of themes that if the otherwise would ensure the safety and efficacy of medicines (Table 1)(16). In fact, the worries about the quality of generic drugs still persist wide range and spur concerns among thallasemics (17).

\section{Conclusions}

Despite the significant role of generic drugs in the medical care of patients especially chronically ill patients, concerns alarm on the quality particularly in developing countries and the ones with

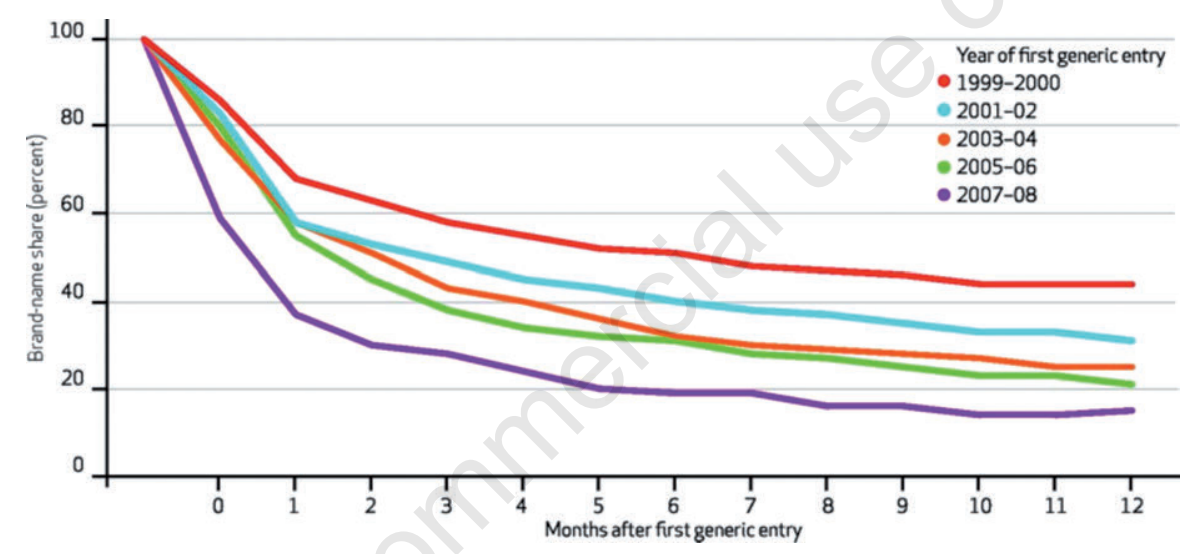

Figure 1. The share of brand-name drugs during 12 months after the generic medicines entered the market.

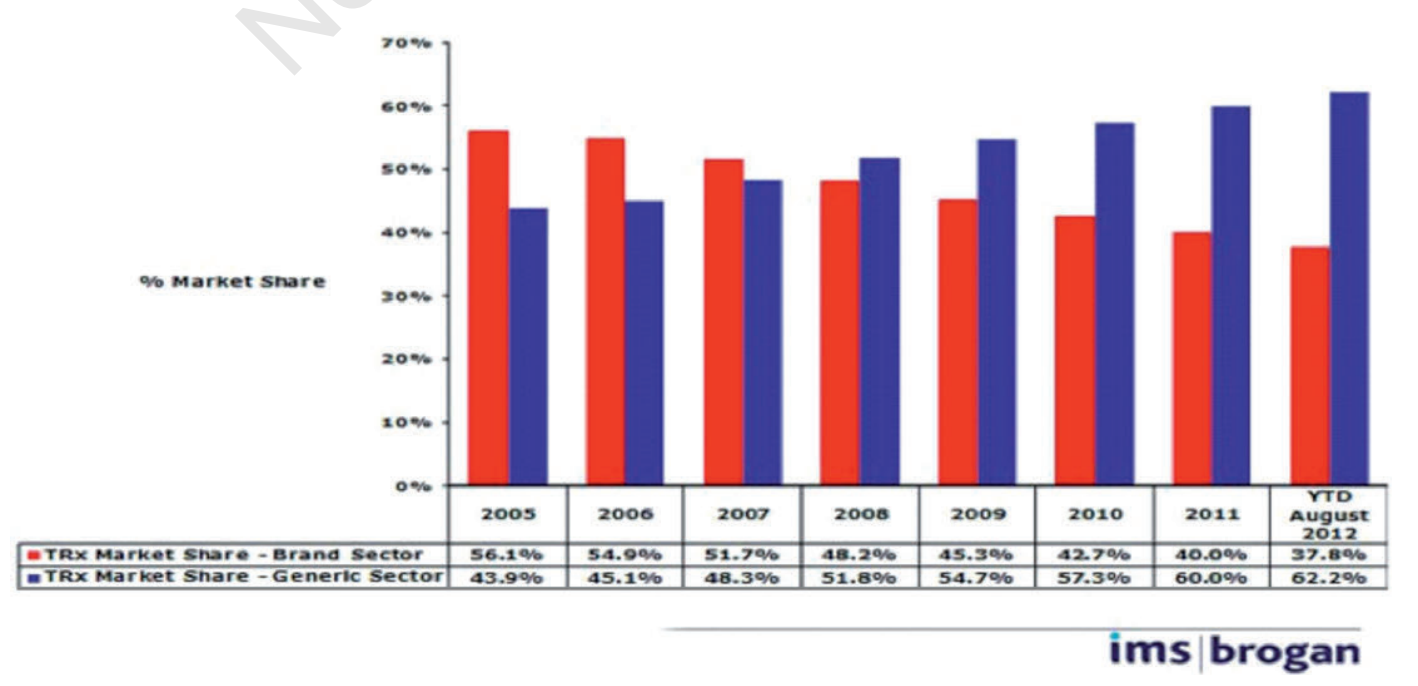

Figure 2. The changes in the share of generic and brand-name between the years 2005 and 2012. 
Table 1. Comparison of key regulatory authority of a few developing countries.

\begin{tabular}{lcccc} 
Country & $\begin{array}{c}\text { Legislative and } \\
\text { regulatory framework }\end{array}$ & $\begin{array}{c}\text { Pharmaco } \\
\text { vigilance }\end{array}$ & GMP compliance & Quality and safety control \\
Argentina & Medium-Low & Low-Medium & Medium & Low-Medium \\
Brazil & Medium-High & Medium & Medium & Medium-High \\
\hline Egypt & Low-Medium & Low-Medium & Medium & Medium \\
China & High & Medium & Medium & Low-Medium \\
\hline India & Low & Low & Low-Medium & Low \\
Peru & Low-Medium & Low-Medium & Medium & Low-Medium \\
Russia & Low-Medium & Medium & Low-Medium & Low-Medium \\
Thailand & Low-Medium & Medium & Low-Medium & Low-Medium \\
\hline Turkey & Medium & Medium-Low & Medium & Low-Medium \\
\hline
\end{tabular}

lower levels of economic freedom. Thallasemics are lifelong consumers of the essential drugs access to which is the most important lifelong challenge. Patient Centered Care suggests the delivery of the adequate and precise information to the recipients of medical services as the priority of the health system. Emotional support for patients is also planned to be a part of the care programs (18). It is therefore imperative to assure patients of the quality of the consuming medicines and avoid the Hobson's choice prescription of the medicines whose quality is in doubt.

To reach the favorable quality, WHO has issued a guideline whose abidance is obligatory for both developing and developed countries. NGOs are likewise responsible for the activities of pharmaceutical companies to clarify. The best example is Bill and Melinda Gates Institute that innovated "Access to Medicine Index" program by which the big pharmaceutical companies were provoked to be accountable and issue licenses to developing countries (20). The Gilead Company licensed its hepatitis $\mathrm{C}$ drugs to India and made the prices drop in Egypt thereby expanding access to the essential medicines $(21,22)$. Thus, the role of NGOs is significant in the clarity about the medicine quality and the changes in the price of brand-name medicines particularly in developing countries.

\section{References}

1. The right of health: note by the Secretary-General, available from http://repository.un.org/handle/11176/171379

2. The world health report 2003 - shaping the future, available from http://www.who.int/whr/2003/en/

3. Musgrove P, Zeramdini R, and Carrin G, Basic patterns in national health expenditure, Bulletin of the World Health Organization 2002, 80 (2).

4. EU options for improving access to medicines, study for the EP ENVI committee, drafted by Cabezón-Ruiz, 2016, available from http://www.europarl.europa.eu/sides/getDoc.do?pubRef=//EP// NONSGML+COMPARL+PE-587.690+01+DOC+PDF+ $\mathrm{V} 0 / / \mathrm{EN} \&$ language $=\mathrm{EN}$

5. Miri M, Tabrizi Namini M, Hadipour Dehshal M, Sadeghian Varnosfaderan, Ahmadvand A, Yousefi Darestani S, Manshadi M. Thalassemia in Iran in Last Twenty Years: the Carrier Rates and the Births Trend. Iranian Journal of Blood and Cancer. 2013;1:11-18.

6. Prera D. Thalassaemia Patients At Risk, the Sunday leader, 2010, available from http://www.thesundayleader.1k/2010/05/ 30/thalassaemia-patients-at-risk/

7. Berndt, Ernst R, and Murray L. Aitken, "Brand Loyalty, Generic Entry and Price Competition in Pharmaceuticals in the
Quarter Century after the 1984 Waxman - Hatch Legislation", International Journal of the Economics of Business 18(2):177 - 201, July 2011.

8. Grabowski H. Are the economics of pharmaceutical research and development Changing, Pharmacoeconomics 2004, 22 supple. 2.

9. Grabowski HG, Kyle M, Mortimer R, Long G, Kirson N. Evolving brand-name and generic drug competition may warrant a revision of the Hatch-Waxman Act. Health Aff . 2011 Nov; 30(11):2157-66.

10. Global Medicines Use in 2020: Outlook and Implications, IMS institution 2012, available from http://www.imshealth. com/en/thought-leadership/quintilesims-institute/reports/global-medicines-use-in-2020

11. Canada's Pharmaceutical Industry and Prospects, 2013, available from https://www.ic.gc.ca/eic/site/lsg-pdsv.nsf/vwapj/ PharmaProfileFeb2014_Eng.pdf/\$file/PharmaProfileFeb2014 Eng.pdf

12. Pogge T, Rimmer M, and Rubenstein M. "Access to Essential Medicines: Public Health and International Law" CambridgeIncentives for Global Public Health: Patent Law and Access to Essential Medicines Vol. 2 (2010). Available at: http://works.bepress.com/matthew_rimmer/74/

13. Generic Drugs, the Center for Drug Evaluation and Research, the US food and drug administration, 2017 available from https://www.fda.gov/Drugs/ResourcesForYou/Consumers/Buy ingUsingMedicineSafely/GenericDrugs/default.htm

14. Facts and Myths About Generic Drugs, Rocky mountain health plans 2017 available from https://www.rmhp.org/learning-center/your-prescription-coverage

15. 2017 index of economic freedom, The Heritage Foundation and The Wall Street Journal available from http://www.heritage.org/index/

16. Healy P, and Pugatch MP, Keeping Medicines Safe Extended, available from https://issuu.com/stockholmnetwork/docs/ know_ip_32

17. Yassmin A. Thalassaemia patients worried about shortage of life-saving drug, The Hindu 2016. available from http://www. thehindu.com/news/cities/bangalore/Thalassaemia-patientsworried-about-shortage-of-life-saving-drug/article 14594686.ec

18. Epstin RM, Richard L, and Street Jr, The Values and Value of Patient-Centered Care, Ann Fam Med March/April 2011 vol. 9 no. $2,100-103$.

19. Essential medicines and health products, WHO guideline 2017, available from http://www.who.int/medicines/publications/essentialmedicines/en/ 
20. Access to Medicine Index 2016, Bill and Melinda Gates foundation. Available from https://accesstomedicineindex.org/

21. Egypt negotiates importing hepatitis $\mathrm{C}$ drug Harvoni at lower price, Thicariopost 2015, available from http://thecairopost. youm7.com/news/151295/inside_egypt/egypt-negotiatesimporting-hepatitis-c-drug-harvoni-at-lower-price
22. Gilead Announces Generic Licensing Agreements to Increase Access to Hepatitis C Treatments in Developing Countries 2014, Gilead Official, available from http://www.gilead.com/ news/press-releases/2014/9/gilead-announces-generic-licensing-agreements-to-increase-access-to-hepatitis-c-treatments-indeveloping-countries 